American J. of Engineering and Applied Sciences 3 (2): 277-285, 2010

ISSN 1941-7020

(C) 2010 Science Publications

\title{
Acrylic Rubber Latex in Ferrocement for Strengthening Reinforced Concrete Beams
}

\author{
D. Raj Kumar and B. Vidivelli \\ Department of Civil and Structural Engineering, \\ Annamalai University, Annamalainagar-608 002, Tamilnadu, India
}

\begin{abstract}
Problem statement: In India, the early deterioration of reinforced concrete structures has become a big social problem in recent years. An essential research is needed for the development of effective repair materials and their execution systems comes to an important issue from the viewpoint of the longevity of infrastructures at present. Ferrocement laminates are introduced to enhance the overall performance of Reinforced Concrete (RC) structures and these days the use of it is a promising technology for increasing the flexural strength of deficient reinforced concrete members. Approach: The repair system aims to provide quantitative repair enhancement as well as extending the life of deteriorated concrete members. This research in particular inspired the initiation of the present work which aimed to develop a material with unique properties and a very wide range of practical applications. The mechanical properties of mortar through difference in polymer content with Acrilic Latex by ferrocement among three different volume fractions of mesh reinforcement were studied. Following the encouraging progress made in the formulation and evaluation of the polymer modified repair mortar, tests were carried out involving the application of the reinforced repair material to the soffit of the reinforced concrete beams of $3 \mathrm{~m}$ length. Results: The levels of damage of the original beams prior to repair did not affect the ultimate load of the strengthened beams tested. The performance of the strengthened beams was compared to the control beams with respect to cracking, deflection and ultimate strength which confirm preeminent results. Conclusion: This accomplished the fact that acrylic rubber latex modified ferrocement is a doable alternative strengthening component for the rehabilitation of reinforced concrete structures. Further developments in these systems will create dramatic improvement into the field of rehabilitation of old privileged structures.
\end{abstract}

Key words: Ferrocement, polymer, mortar, volume fraction, beams, laminates, mechanical properties

\section{INTRODUCTION}

A large number of civil infrastructures around the world are in a state of serious deterioration today. Moreover many civil structures are no longer considered safe due to increase load specifications in the design codes or due to overloading or due to under design of existing structures or due to lack of quality control. In order to maintain efficient serviceability, older structures must be repaired or strengthened so that they meet the same requirements demanded of the structures built today and in future. Ferrocement over the years have gained respect in terms of its superior performance and versatility and now is being used not only in housing industry but its potentials are being continuously explored for its use in retro-fitting and strengthening of damaged structural members. Ferrocement is a type of reinforced concrete commonly constructed of hydraulic cement mortar reinforced with closely spaced layers of relatively small wire diameter mesh. The mesh may be made of metallic or other suitable materials. Thinking ferrocement as a material to be applied to thin walled it is necessary to adjust the material properties to the construction type and acting forces in the structures, to obtain the proper strength, stiffness, cracking control, ductility and impact resistance. Water soluble polymers and aqueous polymer dispersions are often used to improve the properties of mortar. Polymer modified mortars are being used as a popular construction material because of their excellent performance. Polymer-modified mortars are generally superior in the resistance to oxygen diffusion to unmodified mortar. Consequently the use of polymer-modified mortars as repairing and finishing materials can be recommended in order to inhibit the wet corrosion of reinforcing bars in concrete

Corresponding Author: D. Raj Kumar, Department of Civil and Structural Engineering, Annamalai University, Annamalainagar-608 002, Tamilnadu, India Tel: +91 4144 239732/+91 9944077243/+91 9443488394 Fax: +91 4144239732 
structures (Ohama and Demura, 1991). Even powdered polymer-modified mortars can be used in the same manner as those of aqueous polymer-modified mortar for practical application (Afridi et al., 1994). The water retention of the powdered and aqueous polymermodified mortars increases with a rise in polymercement ratio, however the magnitude of the improvement depends upon the types of cement modifiers used, polymer-cement ratio or both (Afridi et al., 1995). When the cement mixtures are mixed with polymer, a large volume of air voids often forms. Kim and Robertson (1997) established a technique involves pre-wetting the cement and sand with plain water before adding the polymer solution or dispersion. Another area of interest for possible future research would be to determine whether differences noted with the additives used still apply to mortars mixed to higher flows and what effect saturating specimens, initially dry cured has on the tensile bond strength. Wet cured polymer mortars appear to have lower bond strengths than dry cured polymer mortars, indicating that the curing method has much to do with the strength gain of polymer-modified mortars (Colville et al., 1999). During the hardening of cement, polymer can fill into the micro cracks, pores and cracks (Gao et al., 2002). Also it has been noticed that with increase in the addition of polymer the water absorption decreases remarkably when polymer cement ratio is small. But when polymer cement ratio exceeds $10 \%$ the change may become unnoticeable (Wu et al., 2002). Ferrocement laminates with skeletal bar can take significant role in strengthening reinforced concrete beams. For flexural strengthening, polymer modified ferrocement laminates were cast and bonded onto the soffits (tension face) of the beams without any change in width of the beams. As this technology emerges, the structural behavior of RC elements strengthened with polymer modified ferrocement laminates needs to be fully characterized. A strengthening method has been also developed by Lamanna et al. (2004) where the strengthening strip is entirely mechanically attached to the concrete surface using multiple small, distributed power-actuated fasteners without any bonding and showed a greater ductility than the beam strengthened with a bonded strip. Besides the studies to meet the requirements of the applications, attention is paid to the mechanism and means of polymer modification. Recently, extensive work has been carried out at Department of Civil and Structural Engineering, Annamalai University on repair and retrofitting of structural members. RC beam specimens subjected to different degrees of distress were retrofitted by using polymer modified ferrocement laminates and their structural behavior was studied in comparison with that of undamaged control beams. The different levels of damage of the original beams prior to repair did not affect the ultimate loads of the strengthened beams tested (Paramasivam et al., 1998). Based on these extensive experimental studies, recommendations were prepared and given for field applications.

\section{MATERIALS AND METHODS}

Experimental investigations consist of the preparation of Acrylic Rubber latex based modified ferrocement elements with different volume fractions of steel mesh reinforcements. Mixes were prepared with locally available coarse aggregates of $20 \mathrm{~mm}$ maximum size, fine aggregates' passing through $4.75 \mathrm{~mm}$ IS sieve and ordinary portland cement conforming to ISI specification. The fineness modulus of the coarse and fine aggregates was 6.73 and 2.5 respectively whereas specific gravities of coarse and fine aggregates were 2.69 and 2.61 respectively. The mechanical properties of ferrocement were detected by attachment of mesh reinforcement with volume fraction 3.55, 5 and $6.43 \%$ with influence of polymer modification on the properties of cement mortar. Different parameters were taken into account regards to the polymer cement ratio and volume fraction of reinforcement. The latex cement composites were prepared containing each of the following four percentages of latex in cement 5, 10, 15 and 20. At percentages higher than 7.5 the latex showed a tendency to coagulate. The w/c ratio for all the composites was maintained at 0.3 . The amount of water calculated included the water present in the latex. The compressive, split tension, flexure and tension test were carried out as per the standard IS procedures. Ultimately to understand the real characteristics of polymer ferrocement composites eight beams were cast and tested under static condition with two points loading. Typical test set up is shown in Fig. 1.

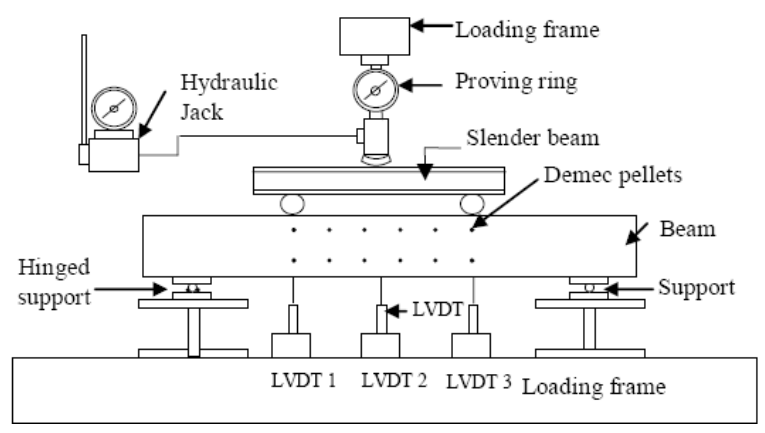

Fig. 1: Typical test set up 
Am. J. Engg. \& Applied Sci., 3 (2): 277-285, 2010

Out of eight beams two control beams were tested to attain the ultimate load. The remaining six beams were retrofitted with polymer modified ferrocement laminates with the same volume fraction of mesh reinforcement as adopted during the preliminary study.

Details of test beam: Eight full-scale rectangular RC beams $125 \mathrm{~mm}$ wide and $250 \mathrm{~mm}$ deep with a total length measures $3.2 \mathrm{~m}$ ( $3 \mathrm{~m}$ effective) span were cast and tested. The beams were reinforced with 2 nos. of $12 \mathrm{~mm} \phi$ at tension and 2 nos. of $8 \mathrm{~mm} \phi$ at compression side with 22 nos. of $6 \mathrm{~mm} \phi$ stirrups spaced $150 \mathrm{~mm} \mathrm{c} / \mathrm{c}$. The yield strength of the reinforcing bars measures $415 \mathrm{~N} \mathrm{~mm}^{-2}$. M20 grade concrete with mix 1: 1.59: 3.12 towards water cement ratio 0.50 is adopted for all beams. Out of the eight beams, two beams (BP1 and BP2) were considered as perfect beams. The remaining six beams BOR1 to BOR6 were damaged by subjecting the beams to a preloading corresponding to $70 \%$ of the ultimate load capacity of the perfect beams and were rehabilitated by three different volume fractions of mesh reinforcement together with addition of $15 \% \mathrm{AR}$ in the polymer modified ferrocement laminates, two beams for each category of rehabilitation. Before rehabilitation the original beam was turned upside down to expose its soffit. Prior to bonding with polymer ferrocement laminates, the soffit of the beams and bonding face of laminates were sandblasted to expose the aggregates and roughen the soffits of the beams so that the distance between the peak and rough of the chipped surface, was approximately $1 \mathrm{~mm}$. The surface was then thoroughly cleaned of debris under an air jet. After surface preparation, the cracks are filled with a low viscous resin named corogrout EPLV. COROCRETIN IHL-18 is applied to the surfaces using trowel and the ferrocement laminate was assembled.

Reinforcing mesh: The principal type of meshes used in the laminate related to their properties is shown in Table 1. Arrangement of mesh reinforcement with volume fraction $(\mathrm{Vr})$ of 3.55 percent contributes with 2 layers of welded mesh $1.51 \% \mathrm{Vr}, 1$ layer of woven mesh $1.44 \% \mathrm{Vr}$ and 4 layers of twisted mesh $0.60 \%$ Vr. Mesh reinforcement for volume fraction of 5percent contributes with 2 layers of welded mesh $1.51 \% \mathrm{Vr}, 2$ layers of woven mesh $2.88 \% \mathrm{Vr}$ and 4 layers of twisted mesh $0.60 \% \mathrm{Vr}$. Mesh reinforcement for volume fraction 6.43 percent contributes with 2 layers of welded mesh $1.51 \% \mathrm{Vr}$, 3layers of woven mesh $4.32 \%$ $\mathrm{Vr}$ and 4 layers of twisted mesh $0.60 \% \mathrm{Vr}$.
Table: 1 Properties of reinforcing mesh

\begin{tabular}{llllll}
\hline Type & Shape & $\begin{array}{l}\text { Fabrication } \\
\text { mode }\end{array}$ & $\begin{array}{l}\text { Gauge } \\
\text { designation }\end{array}$ & $\begin{array}{l}\text { Wire } \\
\text { spacing } \\
(\mathrm{mm})\end{array}$ & $\begin{array}{l}\text { Wire } \\
\text { dia. } \\
(\mathrm{mm})\end{array}$ \\
\hline Expanded & Hexagonal & Twisted & $1 / 2$ No. 22 & 12.54 & 0.72 \\
steel & Square & Woven & $1 / 2$ No. 20 & 4.23 & 0.88 \\
meshes & Square & Welded & 1/2 No. 15 & 15.00 & 1.20 \\
\hline
\end{tabular}

Table 2: Water absorption test on AR modified mortar

\begin{tabular}{|c|c|c|c|c|c|}
\hline \multirow{2}{*}{$\begin{array}{l}\text { Polymer } \\
\text { content } \\
(\%)\end{array}$} & \multicolumn{4}{|c|}{ Percentage of water absorption } & \multirow[b]{2}{*}{$24 \mathrm{~h}$} \\
\hline & $30 \mathrm{~min}$ & $60 \mathrm{~min}$ & $90 \mathrm{~min}$ & $120 \mathrm{~min}$ & \\
\hline 0 & 1.89 & 2.26 & 2.73 & 4.42 & 7.41 \\
\hline 5 & 1.04 & 1.32 & 1.59 & 1.82 & 2.93 \\
\hline 10 & 0.86 & 1.12 & 1.36 & 1.61 & 2.54 \\
\hline 15 & 0.54 & 0.71 & 0.93 & 1.11 & 1.85 \\
\hline 20 & 0.52 & 0.68 & 0.87 & 1.05 & 1.76 \\
\hline
\end{tabular}

Water absorption: Table 2 shows the water absorption test results. The addition of 15 and $20 \%$ of AR latex decreases the $24 \mathrm{~h}$ water absorption of mortar by 75 and $76 \%$. Addition of 5 and $10 \%$ AR latex reduces the $24 \mathrm{~h}$ water absorption nearly by 60 and $66 \%$ respectively. But addition of $5 \%$ AR reduces the 90 min water absorption of mortar by $42 \%$. There is a decrease in 90 min water absorption by 50, 66 and $68 \%$ upon addition of AR at 10, 15 and $20 \%$ respectively. Polymer modified mortar have a structure in which the large pores can be filled with polymer or sealed with continuous polymer films. In general, the effect of polymer filling or sealing increases with a rise in polymer content or polymer cement ratio. These features are reflected in the reduced water absorption of polymer modified mortar.

Compressive, split tensile and flexural strength of AR modified mortar: The compressive and split tensile strength of mortar was found by testing $100 \mathrm{~mm}$ size cubes as well as $100 \times 200 \mathrm{~mm}$ cylinders respectively. Its flexural strength is obtained by testing $600 \times 100 \times 25 \mathrm{~mm}$ flexure beams and tensile strength with $100 \times 200 \times 25 \mathrm{~mm}$ tensile specimens among mesh reinforcement through volume fraction of $3.55,5$ and $6.43 \%$ in a standard manner. To determine the stress strain behavior beam specimens with strain gauges attached to it were kept vertically under UTM. The strains were measured at regular loading interval and results were tabulated. The 28th day strength presented in Fig. 2-5 are mostly the average of the results of three specimens.

Young's modulus for ferrocement under compression: Cylinder specimens were used to find the values of Young's modulus under compression as shown in Table 3. The deformation of cylinder 
Am. J. Engg. \& Applied Sci., 3 (2): 277-285, 2010

specimen's was measured with electrical strain gauges and deflectometers. According to IS 456-2000, young's modulus is given as E $5000 \sqrt{ } \mathrm{f}_{\mathrm{cu}}$. In this mode, unlike tension, the matrix contributes directly the ferrocement strength in proportion to its cross sectional area. The strength and amount of reinforcement are most appropriately defined in terms of stress and volume fraction of reinforcements.

Behavior of ferrocement under tension: Ferrocement is a highly ductile material and its behavior in tension is contributed by mortar and also by mesh reinforcement.

Table 3: Young's Modulus for ferrocement specimens under compression

\begin{tabular}{lll}
\hline & $\mathrm{E}_{\mathrm{c}}\left(\mathrm{N} \mathrm{mm}^{-2}\right)$ & \\
\cline { 3 - 3 } & Theoretical & Experimental \\
\hline $3.55 \% \mathrm{Vr}$ & 28228 & 27729 \\
$3.55 \% \mathrm{Vr}+\mathrm{AR}$ & 29013 & 28136 \\
$5 \% \mathrm{Vr}$ & 31556 & 31356 \\
$5 \% \mathrm{Vr}+\mathrm{AR}$ & 32215 & 31154 \\
$6.43 \% \mathrm{Vr}$ & 31328 & 30435 \\
$6.43 \% \mathrm{Vr}+\mathrm{AR}$ & 30963 & 30460 \\
\hline
\end{tabular}

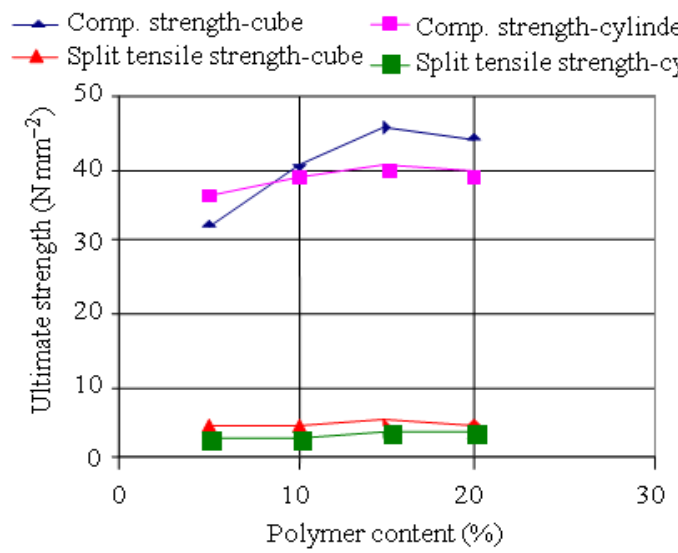

Fig. 2: Polymer content versus strength of AR mortar specimens

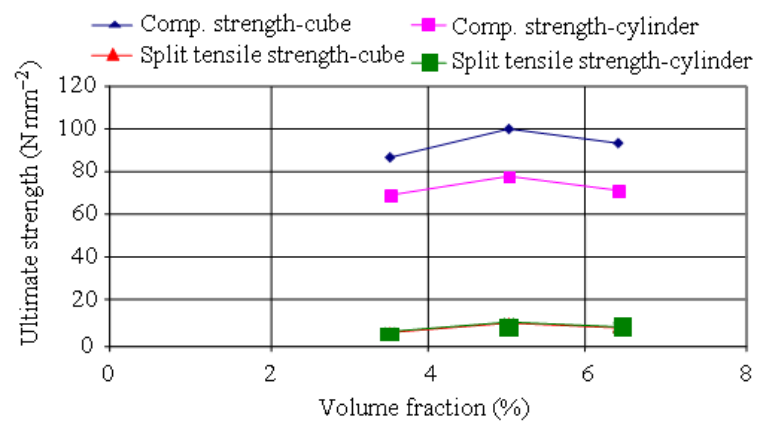

Fig. 3: Volume fraction of mesh versus strength of AR ferrocement specimens
Results obtained from the tension test on steel mesh reinforcement with different volume fraction are shown in Table 4. The size of ferrocement specimen and loading setup is designed as in accordance with ACI committee 549. The test conducted for various volume fraction of reinforcement for meshes and polymer ferrocement specimens with load-strain profile is shown in Fig. 6.

\begin{tabular}{llll}
\multicolumn{6}{l}{ Table 4: Tension test on steel mesh reinforcement } \\
\hline $\operatorname{Vr}(\%)$ & $\begin{array}{l}\text { Yield stress } \\
\left(\sigma_{\mathrm{ry}}\right)\left(\mathrm{N} \mathrm{mm}^{-2}\right)\end{array}$ & $\begin{array}{l}\text { Ultimate stress } \\
\left(\sigma_{\mathrm{ru}}\right)\left(\mathrm{N} \mathrm{mm}^{-2}\right)\end{array}$ & $\begin{array}{l}\text { Youngs modulus } \\
\left(\mathrm{E}_{\mathrm{r}}\right)\left(\mathrm{N} \mathrm{mm}^{-2}\right)\end{array}$ \\
\hline 3.55 & 352 & 683.42 & $1.84 \times 10^{5}$ \\
5.00 & 366 & 698.80 & $2.00 \times 10^{5}$ \\
6.43 & 354 & 689.42 & $1.99 \times 10^{5}$ \\
\hline
\end{tabular}

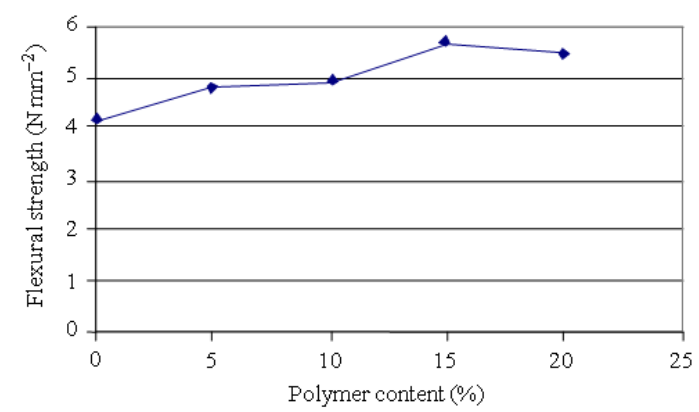

Fig. 4: Polymer content versus flexural strength of AR mortar specimens

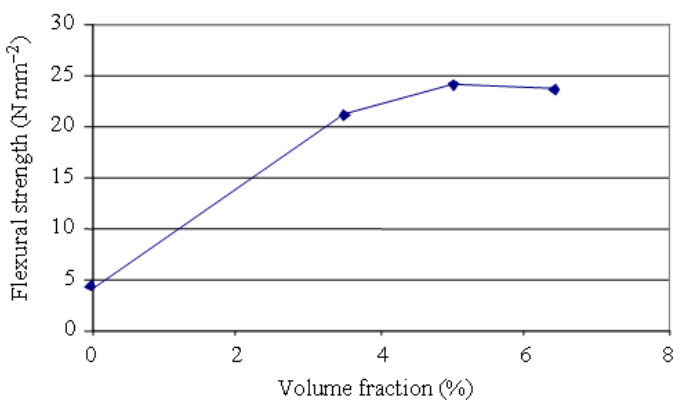

Fig. 5: Volume fraction of mesh versus flexural strength of AR ferrocement specimens

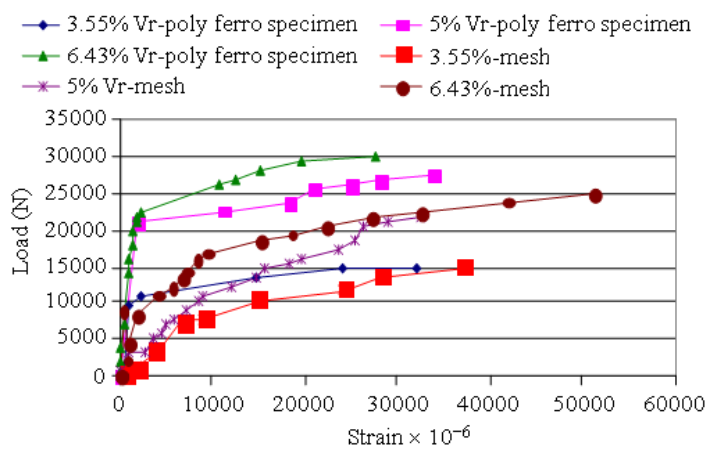

Fig. 6: Load-Strain profile for AR ferrocement specimens and meshes 
Am. J. Engg. \& Applied Sci., 3 (2): 277-285, 2010

Three stages of behavior were observed when the ferrocement elements have been subjected to tensile loads:

- Elastic stage

- Multiple cracking stage

- Ultimate stage

In the elastic stage, moduli of Elasticity $\left(E_{c}\right)$ is expressed as:

$$
\mathrm{E}_{\mathrm{c}}=\mathrm{E}_{\mathrm{m}}\left(1-\mathrm{V}_{\mathrm{r}}\right)+\mathrm{E}_{\mathrm{r}} \mathrm{V}_{\mathrm{r}}
$$

Where:

$\mathrm{E}_{\mathrm{m}}=$ Moduli of elasticity of mortar

$E_{\mathrm{r}}=$ Moduli of elasticity of reinforcement

$\mathrm{V}_{\mathrm{r}}=$ Volume fraction of reinforcement

Naaman and Shah (1971) proposed an empirical formula to predict the first crack stress $\sigma_{\mathrm{cr}}$ of ferrocement as:

$$
\sigma_{\mathrm{cr}}=\sigma_{\mathrm{mu}} 25 \mathrm{~S}_{\mathrm{r}}\left(\mathrm{N} \mathrm{mm}^{-2}\right)
$$

Where:

$\sigma_{\mathrm{mu}}=$ Ultimate strength of mortar

$S_{\mathrm{r}}=$ Specific surface $\left(\mathrm{mm}^{2} \mathrm{~mm}^{-3}\right)$ in the direction of loading

At this stage, strain:

$$
\varepsilon_{\mathrm{cr}}=\sigma_{\mathrm{cr}} / \mathrm{E}_{\mathrm{c}}
$$

During the multiple cracking stages the contribution of mortar to the stiffness of composite decreases progressively. At this stage the youngs modulus of composite is:

$$
E_{c y}=E_{r} V_{r}
$$

Cracking behavior is mainly depending on the volume and dispersion of reinforcement:

$$
\begin{gathered}
\sigma_{\mathrm{cy}}=\sigma_{\mathrm{ry}} \times \mathrm{V}_{\mathrm{r}} \\
\varepsilon_{\mathrm{cy}}=\left\{\left(\sigma_{\mathrm{cy}}-\sigma_{\mathrm{cr}}\right) / \mathrm{E}_{\mathrm{cy}}\right\}+\varepsilon_{\mathrm{cr}}
\end{gathered}
$$

At ultimate stage the load is carried by the mesh reinforcement in the direction of loading. The ultimate strength can be found as:

$$
\sigma_{\mathrm{cu}}=\sigma_{\mathrm{ry}} \times \mathrm{V}_{\mathrm{r}}
$$

where, $\sigma_{\mathrm{ry}}$ is yield stress of reinforcement.
Table 5: Youngs Modulus for ferrocement specimens under tension $\mathrm{E}_{\mathrm{c}}\left(\mathrm{N} \mathrm{mm}^{-2}\right)$

\begin{tabular}{lll} 
Specimen & Theoretical & Experimental \\
\hline $3.55 \% \mathrm{Vr}$ & 32194 & 28829 \\
$3.55 \% \mathrm{Vr}+\mathrm{AR}$ & 31618 & 29013 \\
$5 \% \mathrm{Vr}$ & 34198 & 30556 \\
$5 \% \mathrm{Vr}+\mathrm{AR}$ & 33627 & 31215 \\
$6.43 \% \mathrm{Vr}$ & 35928 & 32435 \\
$6.43 \% \mathrm{Vr}+\mathrm{AR}$ & 35363 & 32460 \\
\hline
\end{tabular}

Table 6: Crack spacing and crack width for ferrocement specimens

\begin{tabular}{lrrlll}
\hline & \multicolumn{2}{l}{ Crack spacing $(\mathrm{mm})$} & Crack width & \\
& - & \multicolumn{1}{l}{ Exp. } & Theo. & Exp. & $\begin{array}{l}\text { No. of } \\
\text { cracks }\end{array}$ \\
\hline $3.55 \% \mathrm{Vr}$ & 14.97 & 16.20 & 0.09 & 0.11 & 5 \\
$3.55 \% \mathrm{Vr}+\mathrm{AR}$ & 13.12 & 13.74 & 0.09 & 0.09 & 3 \\
$5 \% \mathrm{Vr}$ & 9.22 & 10.20 & 0.07 & 0.08 & 3 \\
$5 \% \mathrm{Vr}+\mathrm{AR}$ & 8.87 & 9.75 & 0.06 & 0.07 & 2 \\
$6.43 \% \mathrm{Vr}$ & 13.14 & 14.32 & 0.08 & 0.09 & 4 \\
$6.43 \% \mathrm{Vr}+\mathrm{AR}$ & 13.48 & 13.45 & 0.08 & 0.08 & 3
\end{tabular}

By use of the above expressions the theoretical values for three stages under tension for three different volume fractions of mesh reinforcement for ferrocement specimens were arrived. Further the experimental results checked for precise with the theoretical values as shown in Table 5 .

Crack spacing and crack width of ferrocement specimens: Cracking behavior is mainly dependent on the volume fraction and distribution of reinforcement. In tensile behavior the crack width is a function of specific surface of the reinforcement, where as in the flexural behavior, the crack width depends on the tensile strain in the extreme layer. Based on observations, the average crack spacing and crack width is calculated using equations as provided in British Standard Institution (BS 8110: Part 2) (1985):

$$
\begin{gathered}
\left(\Delta_{\mathrm{l}}\right)=(\theta / \eta) \times \mathrm{l} / \mathrm{S}_{\mathrm{r}} \\
\mathrm{w}_{\max }=3500 / \mathrm{E}_{\mathrm{r}}
\end{gathered}
$$

for $\left(\sigma_{\mathrm{r}} \leq 345 \mathrm{~S}_{\mathrm{r}}\right)$.

$$
\mathrm{W}_{\max }=20 / \mathrm{E}_{\mathrm{r}}\left[175+3.69\left(\sigma_{\mathrm{r}}-345 \mathrm{~S}_{\mathrm{r}}\right)\right]
$$

for $\left(\sigma_{\mathrm{r}}>345 \mathrm{~S}_{\mathrm{r}}\right)$.

Here:

$\Delta_{1}=$ Refers to crack spacing

$\mathrm{S}_{\mathrm{r}}=$ The specific surface in the loading direction in $\mathrm{mm}^{-1}$

$\mathrm{w}_{\max }=$ The maximum crack width in mm

$\sigma_{\mathrm{r}}=$ The steel stress under service load in $\mathrm{N} \mathrm{mm}^{-2}$

$\theta=$ A factor relating average crack spacing to maximum crack spacing

$\eta=$ The ratio of bond strength to matrix tensile strength (for wire meshes $\theta / \eta$ was found empirically approximate to unity) 
Am. J. Engg. \& Applied Sci., 3 (2): 277-285, 2010

Table 6 shows the theoretical crack width and spacing compared with the experimental results.

Ultimate strength: ACI Committee 549 on ferrocement recommends that theory of conventional reinforced concrete analysis can be used for ultimate strength calculations of ferrocement. The principle of equilibrium and compatibility can be used. Since reinforcement is distributed evenly across the cross section, the analysis is quiet tedious because of the trial and error method. A simplified approach was proposed by Paramasivam et al. (1998) to compute ultimate moment by plastic analysis:

$\mathrm{C}=\sigma_{\mathrm{cu}} \mathrm{bx}$

$\mathrm{T}=\sigma_{\mathrm{tu}} \mathrm{h}(\mathrm{h}-\mathrm{x})$

$\sigma_{\mathrm{tu}}=\mathrm{A}_{\mathrm{s}} \mathrm{f}_{\mathrm{y}} / \mathrm{b} \mathrm{h}$

$\mathrm{T}=\mathrm{C}$ then $\mathrm{Mu}=\sigma_{\mathrm{tu}} \mathrm{b}(\mathrm{h}-\mathrm{x}) \mathrm{h} / 2$

Using the above analysis, the theoretical momentcurvature relations for three different volume fraction of ferrocement specimens was calculated as shown in Fig. 7a-c.

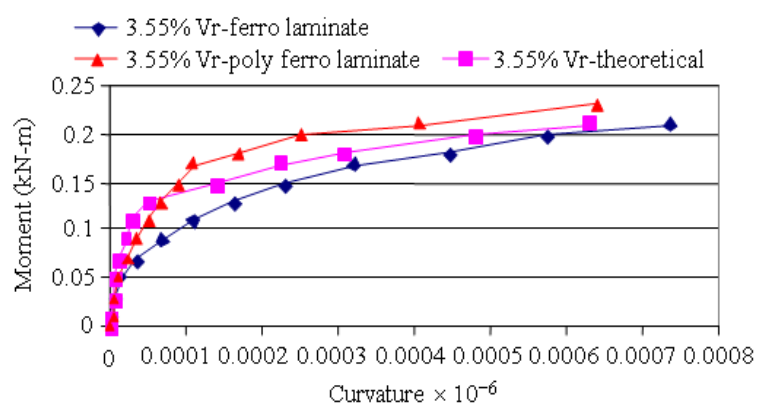

(a)
Deflection calculation: Experimental load-deflection curve of the ferrocement elements show that they can be represented approximately by a tri-linear relation. Accordingly the short term deflection $\delta$ of the ferrocement element is:

$\delta_{\text {cr }}=(23 / 216) \mathrm{L}^{2} / \emptyset_{\mathrm{cr}}$ $\delta=\mathrm{KML}^{2} /\left(\mathrm{E}_{\mathrm{c}} \mathrm{I}_{\mathrm{g}}\right)$, If $\mathrm{M}<\mathrm{M}_{\mathrm{cr}}$

$\delta=\mathrm{KM}_{\mathrm{cr}} \mathrm{L}^{2} /\left(\mathrm{E}_{\mathrm{c}} \mathrm{I}_{\mathrm{g}}\right)+\mathrm{K}\left(\mathrm{M}-\mathrm{M}_{\mathrm{cr}}\right) \mathrm{L}^{2} / \alpha \mathrm{E}_{\mathrm{c}} \mathrm{I}_{\mathrm{cr}}$, If $\mathrm{M}>\mathrm{M}_{\mathrm{cr}}$

Where:

$M=$ The applied moment

$\mathrm{L}=$ The effective span

$I_{g}=$ The moment of inertia of the gross transformed section or gross section

$I_{\mathrm{cr}}=$ The moment of inertia of the cracked section

$\mathrm{K}=\mathrm{A}$ constant depending on loading and boundary conditions, $\alpha$ is a constant

$E_{c}=$ The modulus of elasticity of mortar i.e., $5000 \sqrt{ } f_{c u}$

Using this formula, theoretical deflections are calculated for different loading levels and are compared with the experimental values as shown in Fig. 8a-c.

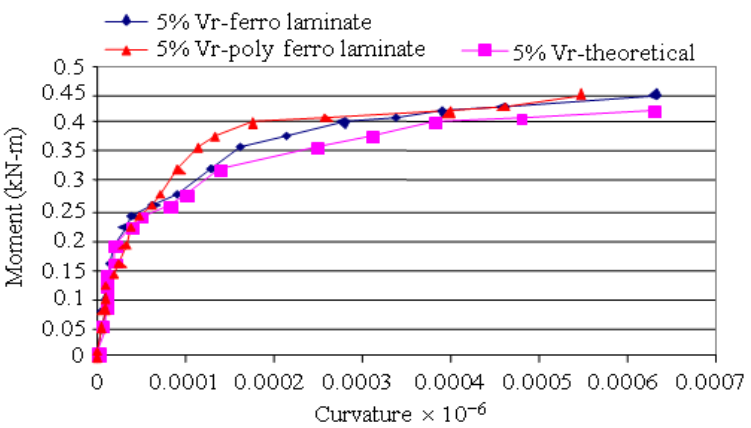

(b)

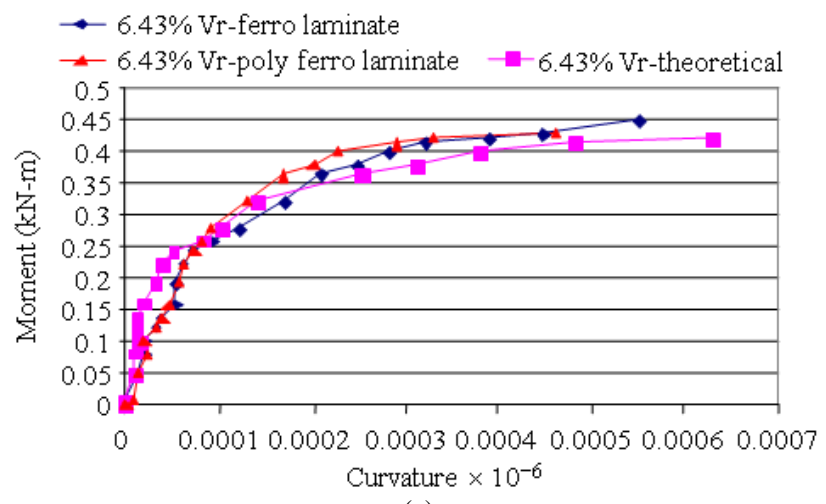

(c)

Fig. 7a-c: Moment curvature relation for AR ferrocement specimens 


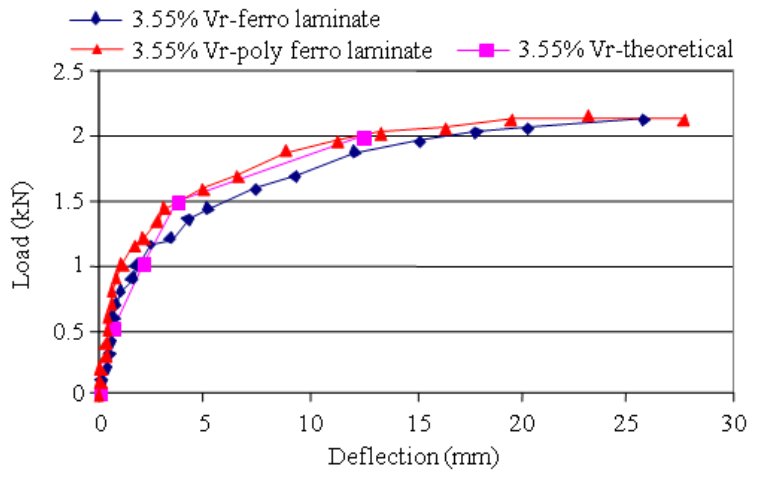

(a)

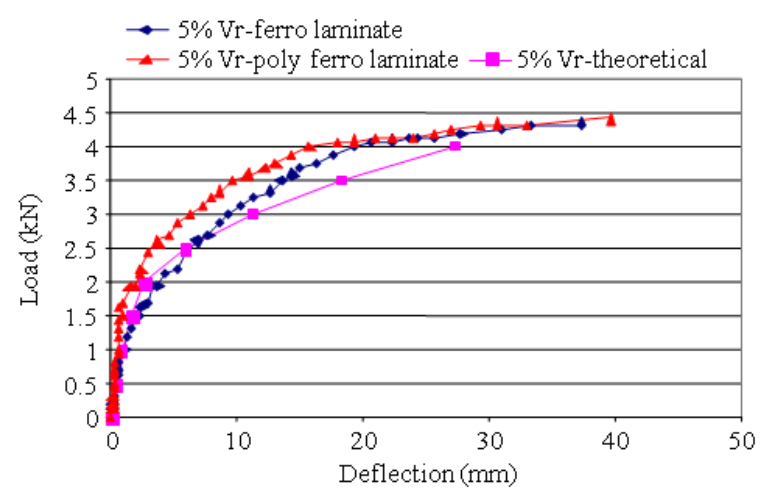

(b)

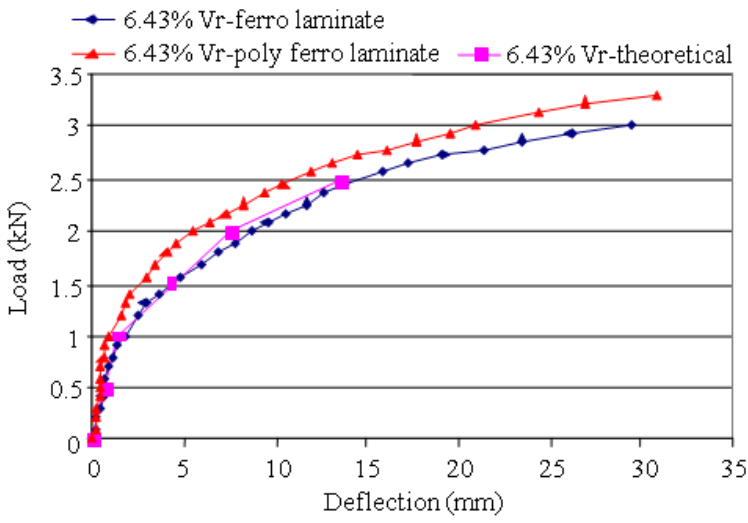

(c)

Fig. 8a-c: Load deflection performances

\section{RESULTS AND DISCUSSION}

Behavior of precracked and rehabilitated beams: All beams were tested under two point loading and also instrumented for the measurement of mid-span deflections and concrete strains for difference positions at the middle of the span. Figure 9 shows the beam with typical cracks after overloading and Fig. 10 shows a strengthened beam to be kept tested for failure. The reading of the deflections was recorded by portable data logger. Cracks spacing along the beam soffits were manually scaled and the average values were recorded. Widths of the cracks were measured with the aid of a hand-held microscope of magnification. Cracks propagation was visually traced and marked with the aid of powerful lamp and magnifying glass and the corresponding loads were recorded on the surface of the test beam. The load and deflection due to static load for beams up to failure were recorded and the cumulative load deflection curves for rehabilitated beams pertain to precracking of $70 \%$ of ultimate load along with perfect beams are shown in Fig. 11.

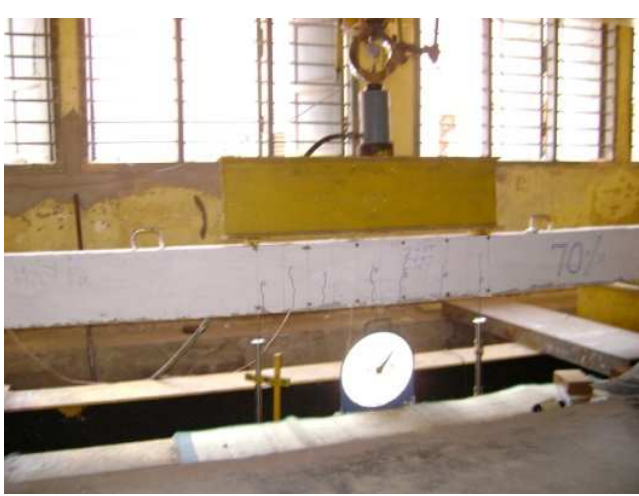

Fig. 9: Beam showing the typical cracks after overloading

Of the perfect beams tested the maximum crack spacing was found to be118 $\mathrm{mm}$. The maximum crack width at the yield stage varied from 0.208$0.246 \mathrm{~mm}$. For the rehabilitated beams the maximum crack width during the yielding stage varied from $0.143-0.286 \mathrm{~mm}$ with spacing ranged from 67$98 \mathrm{~mm}$ at the zone of constant bending moment. 
Am. J. Engg. \& Applied Sci., 3 (2): 277-285, 2010

Table 7: Effectiveness factor for rehabilitated beams

\begin{tabular}{llllllrrrr}
\hline Beam designation & $\mathrm{P}_{\mathrm{y}}(\mathrm{kN})$ & $\mathrm{P}_{\mathrm{u}}(\mathrm{kN})$ & $\delta_{\mathrm{y}}(\mathrm{mm})$ & $\delta_{\mathrm{u}}(\mathrm{mm})$ & $\mathrm{A}_{\mathrm{e}}\left(\mathrm{mm}^{2}\right)$ & $\mathrm{P}_{\mathrm{e} 1}(\mathrm{kN})$ & $\mathrm{P}_{\mathrm{e} 2}(\mathrm{kN})$ & $\mathrm{F}_{1}$ & $\mathrm{~F}_{2}$ \\
\hline BP1 & 42.00 & 52.50 & 39.45 & 92.90 & 3019.20 & 80.13 & 98.90 & 1.00 & 1.00 \\
BP2 & 43.50 & 54.00 & 40.20 & 93.80 & 2096.10 & 81.85 & 101.50 & 1.00 & 1.00 \\
BOR1 & 62.00 & 67.50 & 33.50 & 66.35 & 2314.12 & 92.55 & 122.80 & 1.14 & 1.22 \\
BOR2 & 63.50 & 69.50 & 34.65 & 63.50 & 2298.76 & 91.79 & 116.37 & 1.13 & 1.16 \\
BOR3 & 66.00 & 73.50 & 31.55 & 88.70 & 3742.30 & 125.13 & 185.55 & 1.54 & 1.85 \\
BOR4 & 66.50 & 74.50 & 31.00 & 90.20 & 3691.54 & 125.85 & 193.49 & 1.55 & 1.93 \\
BOR5 & 63.00 & 69.50 & 35.25 & 77.50 & 3212.13 & 107.15 & 138.51 & 1.32 & 1.38 \\
BOR6 & 61.50 & 71.40 & 34.85 & 75.30 & 3149.18 & 105.42 & 132.88 & 1.30 & 1.31 \\
\hline
\end{tabular}

$\mathrm{P}_{\mathrm{y}}$ : Load on perfect beam at yield stage; $\mathrm{P}_{\mathrm{u}}$ : Load on perfect beam at ultimate stage; $\delta_{\mathrm{y}}$ : Deflection of perfect beam at yield stage; $\delta_{\mathrm{u}}$ : Deflection of perfect beam at ultimate stage; $\mathrm{P}_{\mathrm{e} 1}$ : Equivalent elastic force using energy approach; $\mathrm{P}_{\mathrm{e} 2}$ : Equivalent elastic force using deflection approach; $\mathrm{A}_{\mathrm{e}}$ : Equivalent area; $F_{1}$ : Effectiveness factor using energy approach; $F_{2}:$ Effectiveness factor using deflection approach

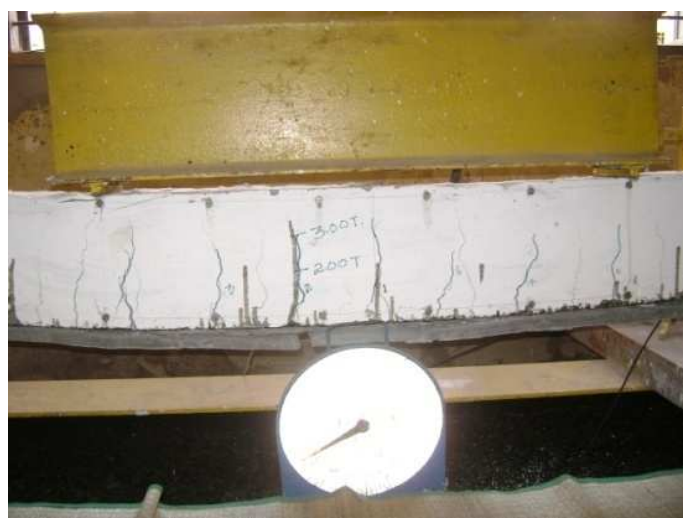

Fig. 10: Strengthened beam tested for failure

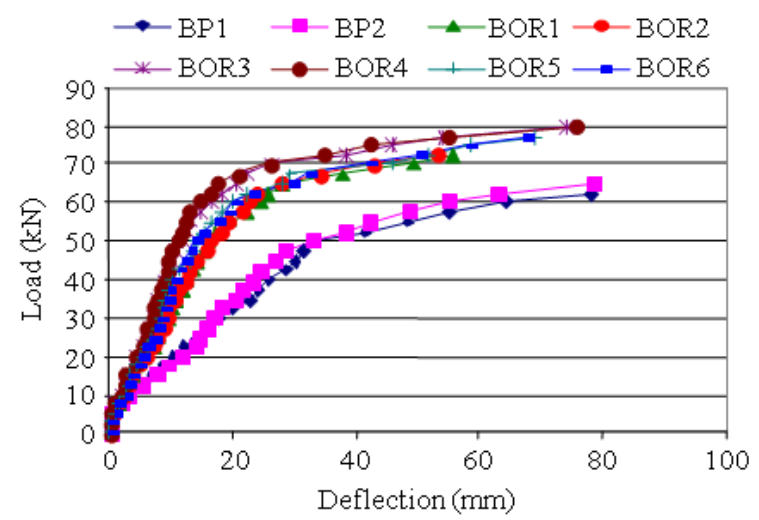

Fig. 11: Load deflection behaviors of perfect and rehabilitated beams

The results show that the flexural strength of the beams improved after strengthening by about $14-25 \%$, the upper bound correspond to beams with sustained composite action, (BOR3 and BOR4) while the lower values were reported for beams, with early loss of composite action (BOR1 and BOR2). The low level of damage caused to beam prior to repair does not seem to affect its ultimate strength after strengthening. A reduction in the volume fraction of reinforcement
$(3.55 \% \mathrm{Vr})$ in the ferrocement laminate reduced the flexural strength correspondingly.

Evaluation of overall performance: The overall performance of the rehabilitated beams has been evaluated by considering the equivalent elastic forces using energy and deflection approaches. The effectiveness factors were evaluated using energy $\left(F_{1}\right)$ and deflection $\left(\mathrm{F}_{2}\right)$ approach for the beams as shown in Table 7.

The equivalent elastic forces $\mathrm{P}_{\mathrm{e} 1}$ and $\mathrm{P}_{\mathrm{e} 2}$ are computed as:

$$
\begin{aligned}
& \mathrm{P}_{\mathrm{e} 1}=\sqrt{ }\left[2 \mathrm{~A}_{\mathrm{e}} \mathrm{P}_{\mathrm{y}}\right] / \delta_{\mathrm{y}} \\
& \mathrm{P}_{\mathrm{e} 2}=\mathrm{P}_{\mathrm{y}}\left[\delta_{\mathrm{u}} / \delta_{\mathrm{y}}\right] \\
& \mathrm{F}_{1}=\mathrm{P}_{\mathrm{e} 1 \text { (rehabilitated) }} / \mathrm{P}_{\mathrm{e} 2 \text { (conventional) }} \\
& \mathrm{F}_{2}=\mathrm{P}_{\mathrm{e} 2 \text { (rehabilitated) }} / \mathrm{P}_{\mathrm{e} 2 \text { (conventional) }}
\end{aligned}
$$

The effectiveness factor $F_{1}$ for rehabilitated beams varies between 1.13 and 1.55 and $F 2$ varies between 1.16 and 1.93.It was found that polymer ferrocement with 5\% volume fraction exhibits superior performance than the other laminates.

\section{CONCLUSION}

Based on the above results and analysis of these results, the following conclusions can be drawn:

- The flexural and compressive strength of polymer modified mortars are improved over unmodified mortar by adding $15 \%$ of Acrylic Rubber Latex through 5\% volume fraction of mesh reinforcement in the polymer ferrocement specimens. While noticing the tensile strength establishes the fact that all the chosen volume fractions of mesh reinforcement hold best results. From this it is clear that, the strength properties are based on the provision of percentage of polymer, volume fraction and the arrangement of reinforcement

- Youngs modulus under tension is greater than the value of Youngs modulus under compression. 
Polymer modified ferrocement with 5\% volume fraction of reinforcement was higher in its Youngs modulus under compression and $6.43 \%$ volume fraction of reinforcement being higher under tension. Hence mortar contributes in it's towards the cracking stage and the steel towards the multiple cracking and ultimate stage

- Based on the other properties of ferrocement it has been concluded that it is a low cost and good material to restoring the load carrying capacity of the member. Hence it can be used as a rehabilitation material especially for beams without skeletal steel

- Result from the test program shows that by incorporation of polymers, the mesh reinforcement with volume fraction $5 \%$ appropriate for compressive as well as flexural members and $6.43 \%$ precise for tensile members

- The performance of the strengthened beams was compared to the control beams with respect to cracking, deflection and ultimate strength. The result show that all the strengthened beams exhibited higher ultimate capacity. A decreased in the volume fraction of reinforcement from 5-3.55\% resulted in a reduction in strength. The presence of these laminates has an inhibiting effect on the tensile cracks so as the crack spacing and crack width were reduced after strengthening. The deflections, the rebar strains and the crack width in the rehabilitated beams have reduced significantly compared to the perfect beams. Rehabilitated beams exhibit an increase of $79 \%$ in its overall performance compared to the perfect beams

\section{ACKNOWLEDGEMENT}

The researchers wish to thank the technical support rendered by Dr. C. Antony Jeyasehar, Professor and Head, Department of Civil and Structural Engineering, Annamalai University. P.G students and laboratory staffs of Civil and Structural Engineering are also gratefully acknowledged.

\section{REFERENCES}

Afridi, M.U.K., Z.U. Chaudhary, Y. Ohama, K. Demura and M.Z. Iqbal, 1994. Strength and elastic properties of powdered and aqueous polymer-modified mortars. Cem. Conc. Res., 24: 1199-1213. DOI: 10.1016/0008-8846(94)90105-8.
Afridi, M.U.K., Y. Ohama, M.Z. Iqbal and K. Demura, 1995. Water retention and adhesion of powdered and aqueous polymer-modified mortars. Cem. Conc. Compos., 17: 113-118. DOI: 1O.1016/09589465(95)00007-Y

British Standard Institution (BS 8110: Part 2), 1985. Structural use of concrete. Code of practice for special circumstances (AMD 5914) (AMD 12061) (AMD 16017) (Obsolescent but remains current). http://products.ihs.com/cis/Doc.aspx?AuthCode $=\&$ DocNum $=277239$

Colville, J., A.M. Amde and M. Miltenberger, 1999. Tensile bond strength of polymer modified mortar. J. Mater. Civil Eng., 11: 1-5. DOI: 10.1061(ASCE)0899-1561(1999)11:1(1)

Gao, J.M., C.X Qian, B. Wang and K. Morino, 2002 Experimental study on properties of polymermodified cement mortars with Silica fume. Cem. Conc. Res., 32: 41-45. DOI: 10.1016/S00088846(01)00626-3

Kim, J.H. and R.E. Robertson, 1997. Prevention of air void formation in polymer-modified cement mortar by pre-wetting. Cem. Conc. Res., 27: 171-176. DOI: 10.1016/S0008-8846(97)00001-X

Lamanna, A.J., L.C. Bank and D.W. Scott, 2004. Flexural strengthening of reinforced concrete beams by mechanically attaching fiber-reinforced polymer strips. J. Compos. Constr., 8: 203-210. DOI: 10.1061/(ASCE)1090-0268(2004)8:3(203)

Naaman, A.E. and S.P. Shah, 1971. Tensile tests of ferrocement. J. Proc., 68: 693-698. http://www.concrete.org/PUBS/JOURNALS/OLJD etails.asp?Home $=$ JP\&ID=7233

Ohama, Y. and K. Demura, 1991. Pore size distribution and oxygen diffusion resistance of polymermodified mortars. Cem. Conc. Res., 21: 309-315. DOI: 10.1016/0008-8846(91)90012-7

Paramasivam, P., C.T.E. Lim and K.C.G. Ong, 1998. Strengthening of RC beams with ferrocement laminates. Cem. Conc. Compos., 20: 53-65. DOI: 10.1016/S0958-9465(97)0068-1

Wu, K.R., D. Zhang and J.M. Song, 2002. Properties of polymer-modified cement mortar using preenveloping method. Cem. Conc. Res., 32: 425-429. DOI: $10.1016 / \mathrm{S} 0008-8846(01) 00697-4$ 